\title{
Multifocal brown tumor of the maxilla and mandible in primary hyperparathyroidism - diagnostic challenges and literature review
}

\section{Wieloogniskowy guz brunatny kości szczęki i żuchwy w przebiegu pierwotnej nadczynności przytarczyc (PNP) - trudności diagnostyczne i przegląd piśmiennictwa}

\author{
Bartosz Gogolewski ${ }^{1, B, D-F}$, Magdalena Jędrusik-Pawłowska ${ }^{7, A, C F}$, Bogna Drozdzowska ${ }^{2, C, D, F}$ \\ ${ }^{1}$ Department of Maxillofacial Surgery, The St. Barbara Provincial Specialist Hospital No 5 - Trauma Center, Sosnowiec, Poland \\ ${ }^{2}$ Department of Pathology, School of Medicine with the Division of Dentistry, Medical University of Silesia, Zabrze, Poland \\ A - research concept and design; $B$ - collection and/or assembly of data; $C$ - data analysis and interpretation; \\ $D$ - writing the article; $E$ - critical revision of the article; $F$ - final approval of the article
}

Address for correspondence

Bartosz Gogolewski

E-mail: b_gogolewski@wp.pl

Funding sources

None declared

Conflict of interest

None declared

Received on August 1, 2017

Reviewed on September 29, 2017

Accepted on November 14, 2017

D0I

$10.17219 / \mathrm{dmp} / 80300$

Copyright

○ 2017 by Wroclaw Medical University

and Polish Dental Society

This is an article distributed under the terms of the

Creative Commons Attribution Non-Commercial License

(http://creativecommons.org/licenses/by-nc-nd/4.0/)

\begin{abstract}
Multifocal brown tumors are a rare complication of primary hyperparathyroidism (PHPT). The reported prevalence of PHPT-related brown tumor is 3-4\%. The tumor may histologically resemble any giant cell tumor of the jaws; hence, diagnostic errors or a delayed diagnosis of PHPT, when the lesion is the first clinical manifestation of this disease.

We present a 27 -year-old patient at 17-week gestation, who was diagnosed with an expansile mass in the left maxilla. Diagnostic tests also revealed two osteolytic lesions in the mandible.

The patient underwent left maxillary segmental resection; the tumor was resected en bloc with teeth 25, 26. Histology confirmed the primary diagnosis of giant cell tumor. The observation was continued on an outpatient basis. Following delivery, progression of mandibular osteolytic lesions and maxillary tumor recurrence were found. Blood chemistry panel was ordered and the results raised a suspicion of primary hyperparathyroidism. Subsequent diagnostic tests revealed lower right parathyroid adenoma. Parathyroidectomy resulted in an almost complete regression of the mandibular lesions and a slight regression of the maxillary tumor.

The paper presents diagnostic challenges associated with brown tumors as well as clinical, radiological, biochemical and histological manifestations thereof. The effect of pregnancy on the course of primary hyperparathyroidism is discussed and a diagnostic/therapeutic scheme is proposed when giant cells are present in a biopsy specimen.
\end{abstract}

Key words: primary hyperparathyroidism, brown tumor of the maxilla/mandible, giant cell tumor of the maxilla/mandible, pregnancy epulides

Słowa kluczowe: pierwotna nadczynność przytarczyc, guz brunatny szczęki i żuchwy, guz olbrzymiokomórkowy szczęki i żuchwy, guzy ciążowe 
Primary hyperparathyroidism (PHPT) is an endocrine disorder (hypersecretion of parathyroid hormone) caused by parathyroid adenoma, hyperplasia or cancer. The disease is frequently associated with asymptomatic hypercalcemia, hypophosphatemia, hypercalciuria and increased bone resorption. Longstanding hypercalcemia and hypercalciuria may result in nephrolithiasis and heart rhythm abnormalities visible on ECG. ${ }^{1,2}$ PHPT most often develops in women over the age of 50 . The most common cause is a parathyroid adenoma (80-85\%), although it can be difficult to distinguish between a normal and an abnormal gland, with multigland hyperplasia (15\%) and carcinoma (1-2\%) developing afterwards.,3-9

Parathyroidectomy is the treatment of choice for symptomatic and progressive PHPT. ${ }^{9-11}$

Multifocal brown tumors are a rare complication of hyperparathyroidism. The reported prevalence of PHPTrelated brown tumor is $3-4 \% .^{12}$ Brown tumors develop in response to elevated serum levels of parathyroid hormone and can affect the long bones, clavicle, scapula, ribs, pelvic bones, mandible and other craniofacial bones, and the spine. ${ }^{1,11}$ A microscopic examination shows multinucleated giant cells with hemosiderin imparting the brown color and hence the name of the tumor. ${ }^{2,4,9,11,13}$ Bone manifestations are associated with elevated serum alkaline phosphatase. The brown tumor of hyperparathyroidism is histologically very similar to central giant cell lesions (CGCL), a heterogenous group of jaw lesions. Therefore, a histology report must be confronted with the results of the clinical examination, laboratory tests and diagnostic imaging. Otherwise, diagnostic errors or a delay in diagnosis may ensue..$^{8,10,12}$

\section{Objectives}

Brown tumors of the maxilla and mandible may be the first clinical manifestation of PHPT. The aim of this report is to draw the attention of dentists, oral and maxillofacial surgeons to this entity and to emphasize the importance of calcium and phosphorus metabolism testing in patients with craniofacial bone pathologies.

\section{Case report}

A 27-year-old patient at 17-week gestation was referred to the Outpatient Clinic of Oral and Maxillofacial Surgery at the Provincial Specialist Hospital No 5 in Sosnowiec with expansile mass in the left maxilla. She gave a 12-month history of a slow painless growth of the tumor, which she first observed following the extraction of teeth 27 and 28. A physical examination revealed cardiac arrhythmia ( $1^{\text {st }}$ degree atrioventricular block), mitral valve regurgitation, colloid nodule of the thyroid gland (confirmed on fine needle aspiration biopsy), nephrolithiasis (ultrasonography revealed calcium oxalate renal cal- culi) and pregnancy-related anemia (RBC 2.92 T/L; HGB $8.6 \mathrm{~g} / \mathrm{dL}$; HCT 26.0\%). Four months before she had been hospitalized in an orthopedic department and underwent the excision of $1 / 2$ of the lateral end of the right clavicle due to giant cell tumor confirmed on histology.

During her $1^{\text {st }}$ appointment, a tumor biopsy was obtained for histological examination, which revealed a giant cell tumor.

Due to the rapid growth of the tumor during pregnancy, a decision was made together with the attending obstetrician to hospitalize and operate on the patient in the Department of Oral and Maxillofacial Surgery. Prior to surgery, the patient underwent a cardiological examination and a craniofacial MRI with corT2, corT1, corSTIR, sagT1, sagT2, axT1, axT2, axSTIR and corMERGE sequences, but no contrast enhancement. An MRI was selected, as it posed the least danger to the fetus. The examination revealed a $32 \times 26 \times 18 \mathrm{~mm}$ mass $(\mathrm{TR} \times \mathrm{AP} \times \mathrm{CC})$ adjacent to the distal surface of tooth 26 , infiltrating the maxilla, bulging into the lumen of the left maxillary sinus and infiltrating the buccal soft tissues (Fig. 1). Also, 2 osteolytic lesions were visualized in the mandible; one sized $19 \times 10 \times 10 \mathrm{~mm}$ at teeth $41-34$, causing disruption of the lower mandibular cortex and tooth 32 and 33 root resorption. The other, $11 \mathrm{~mm}$ in diameter, was located at the root of tooth 45; cortical thinning was also noted (Fig. 2). The maxillary tumor presented as exophytic nonpedun-

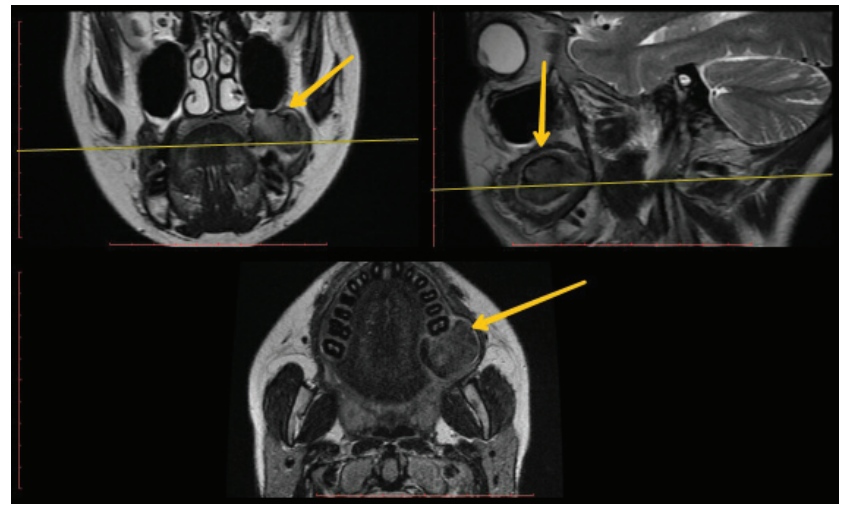

Fig. 1. Craniofacial MRI prior to surgery for maxillary tumor - axial, sagittal and coronal views (yellow arrows)

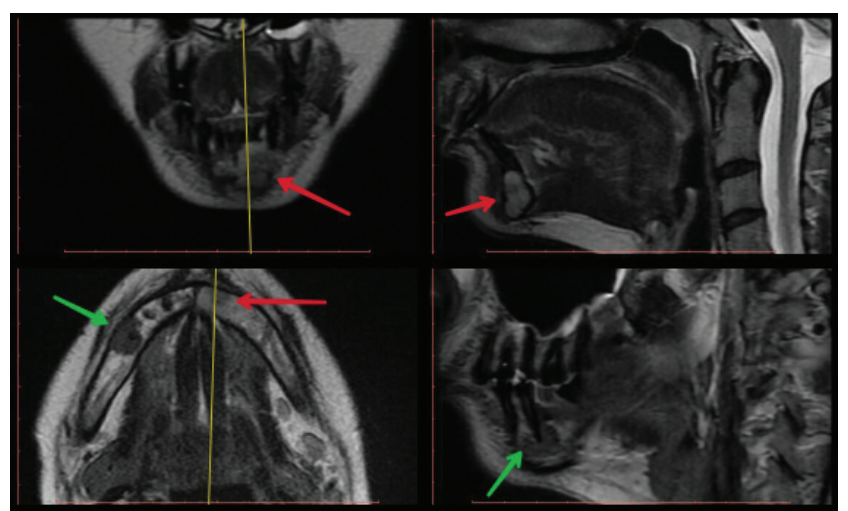

Fig. 2. Craniofacial MRI prior to surgery; 2 osteolytic foci in the mandible - at teeth 41-34 (red arrows) and at the root of tooth 45 (green arrows) 
culated epulis-like lesion; teeth 25 and 26 were embedded in the tumor and showed pathologic mobility but no features of periodontal disease. The larger mandibular lesion was palpable as a painful elastic and soft mass in the mandibular vestibule covered with normal mucosa. The smaller lesion was symptomless. A physical examination revealed a late systolic murmur; ECG demonstrated PQ interval prolongation consistent with $1^{\text {st }}$ degree atrioventricular block.

The patient was operated on at 24-week gestation under general anesthesia; a left maxillary segmental resection was performed; the tumor was resected en bloc with teeth 25,26 , alveolar recess of the maxillary sinus and safety margins. The defect was reconstructed using the neighboring tissues (Fig. 3). The patient made an uneventful convalescence and was discharged 7 days after surgery in good local and general condition. Histology confirmed the primary diagnosis of a giant cell tumor. All surgical margins were free of the tumor except for the hard palate margin (Fig. 4A, 4B).

The patient attended the Outpatient Clinic of Oral and Maxillofacial Surgery for follow-up appointments until delivery. Follow-up craniofacial computed tomography was performed at 5 months of surgery using a 16-row spiral CT scanner, a slice thickness of 2.5 and $1.25 \mathrm{~mm}$ and reconstruction interval of $0.6 \mathrm{~mm}$, prior to and after contrast medium administration (Ultravist). The obtained

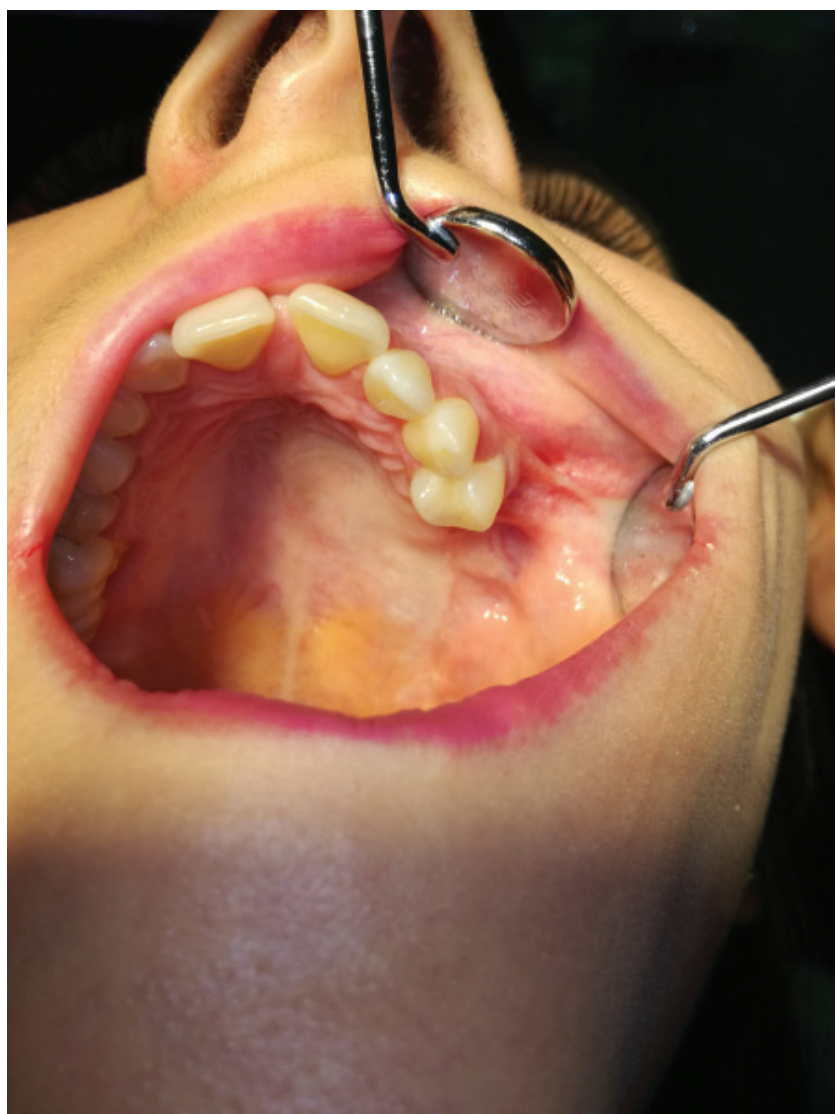

Fig. 3. Intraoral image -8 weeks of left maxillary segmental resection en bloc with teeth 25 and 26
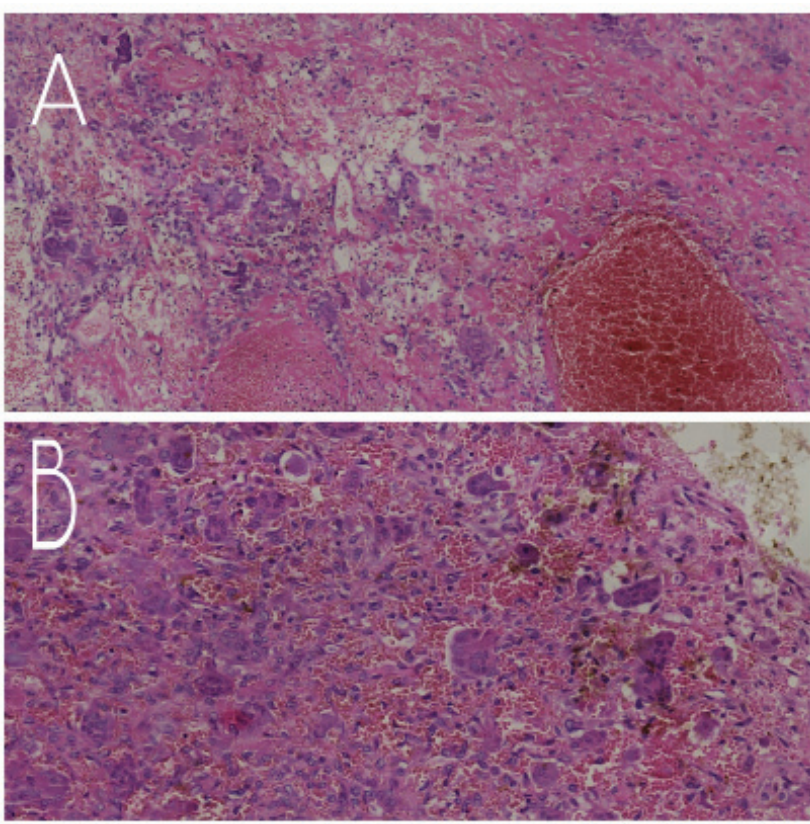

Fig. 4. Microscopic examination of the brown tumor. A. connective tissue with hemorrhage foci and aggregations of multinucleated giant cells (osteoclasts) (20 x magnification, H\&E stain). B. aggregations of multinucleated giant cells (osteoclasts), hemorrhage foci and hemosiderinladen macrophages (60 x magnification, H\&E stain)

scans revealed local recurrence of the maxillary tumor at the surgical site. A $15-\mathrm{mm}$ mass infiltrated the alveolar process in the area of teeth 23 and 24, penetrated the nasal cavity and inferior nasal concha (Fig. 5). The examination also showed progression of the pathologic process within the mandible: the lesion located at teeth 41-34 was almost twice the size of the one visualized on MRI $(25.6 \times 8.4 \times 17.2 \mathrm{~mm}$ vs $19 \times 10 \times 10 \mathrm{~mm})$. The lesion situated at tooth 45 did not change (Fig. 6). A blood chemistry panel was ordered, whose results, along with those of imaging examinations, raised suspicion of primary hyperparathyroidism: $\mathrm{Ca}^{+2}-1.8 \mathrm{mmol} / \mathrm{L}$ (reference range 0.98-1.21 mmol/L); parathyroid hormone - $653 \mathrm{pg} / \mathrm{mL}$ (reference range 10-62 pg/dL).

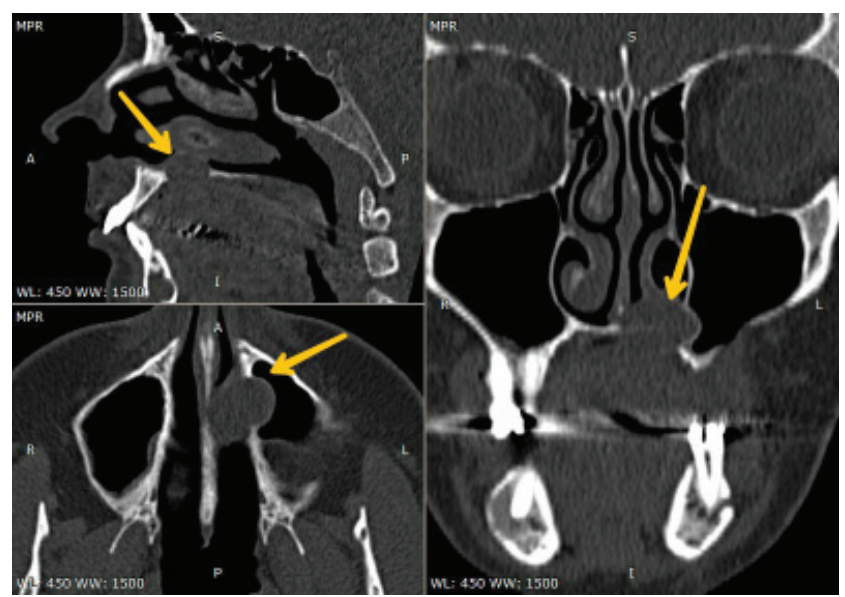

Fig. 5. Craniofacial CT - 5 months of left maxillary segmental resection; pathologic mass at the alveolar processes of teeth 23 and 24, penetrating the nasal cavity (yellow arrows) 


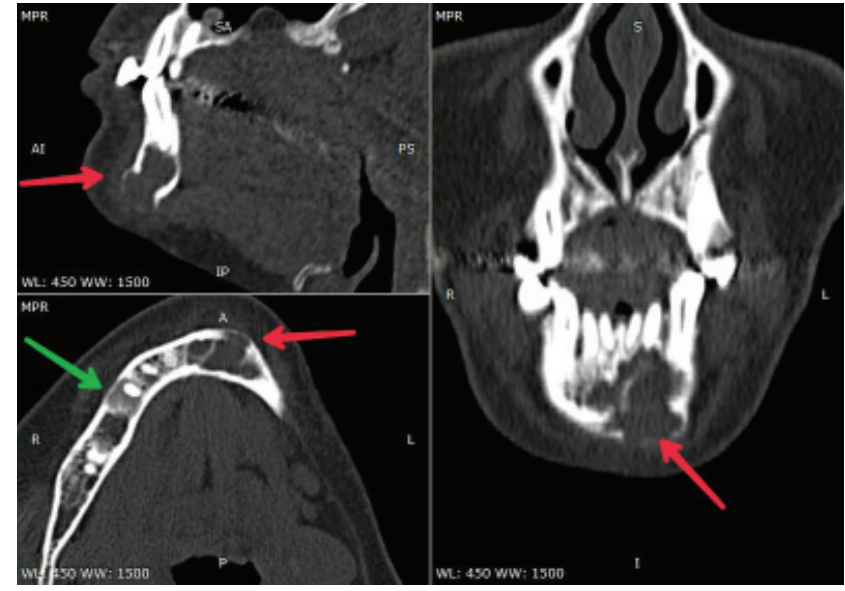

Fig. 6. Craniofacial CT - 5 months of left maxillary segmental resection; osteoIytic lesions in the mandible - at teeth 41-34 causing disruption of the lower mandibular cortex (red arrows) and at the root of tooth 45 (green arrows)

The patient was referred to the Center of Oncology at Maria Sklodowska-Curie Memorial Institute, Gliwice, with suspected parathyroid cancer. In June 2016 (7 months of segmental resection of maxilla) she underwent right inferior parathyroidectomy in the Department of Oncologic and Reconstruction Surgery. Intraoperative PTH assay was performed; histology revealed a parathyroid adenoma.

The patient continued follow-up visits in the Outpatient Clinic of Oral and Maxillofacial Surgery. At 6 months after the parathyroidectomy, $\mathrm{PTH}$ and $\mathrm{Ca}^{+2}$ were within normal range; calcium replacement was not required. An orthopantomogram revealed higher density areas within the pathologic osteolytic lesions of the mandible, whereas the osteolytic lesion of the maxilla seen in the area of tooth 24 showed only slight regression (Fig. 7).

Follow-up craniofacial computed tomography performed at 12 months following the parathyroidectomy revealed further regression of mandibular lesions. The osteolytic focus at tooth 45 was no longer observed; the lesion at teeth $41-34$ became reduced to $8 \times 4 \times 6 \mathrm{~mm}$ and extended between teeth 31 and 33 (Fig. 8). The osteolytic lesion of the maxilla still showed only slight regression (Fig. 9). The patient was referred for femur densitometry;

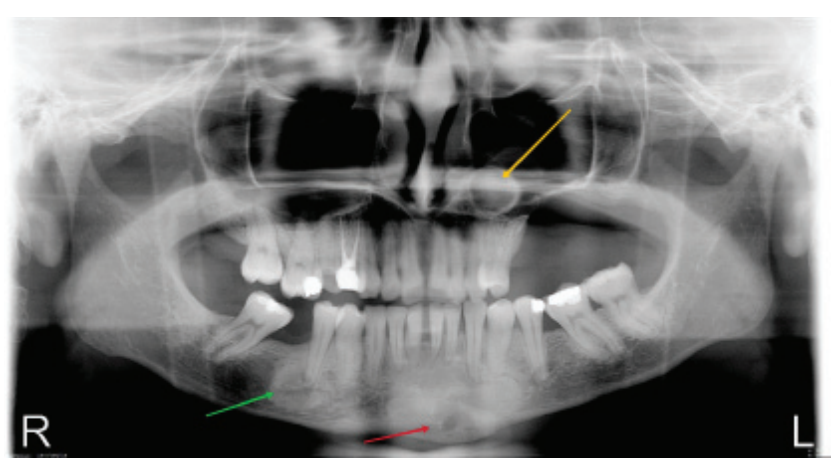

Fig. 7. Orthopantomogram - 6 months of parathyroidectomy; higher density of osteolytic foci at tooth 45 (green arrow) and teeth 41-34 (red arrow); slight regression of the osteolytic lesion within the maxilla (yellow arrow)

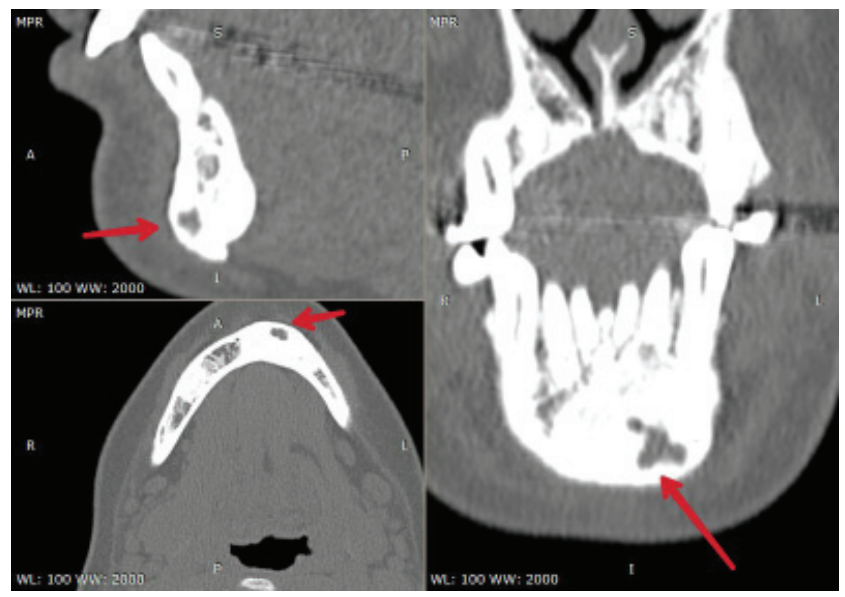

Fig. 8. Craniofacial CT - 12 months of parathyroidectomy; partial regression of mandibular lesion at teeth 41-34 (red arrows); complete regression of the osteolytic focus at tooth 45

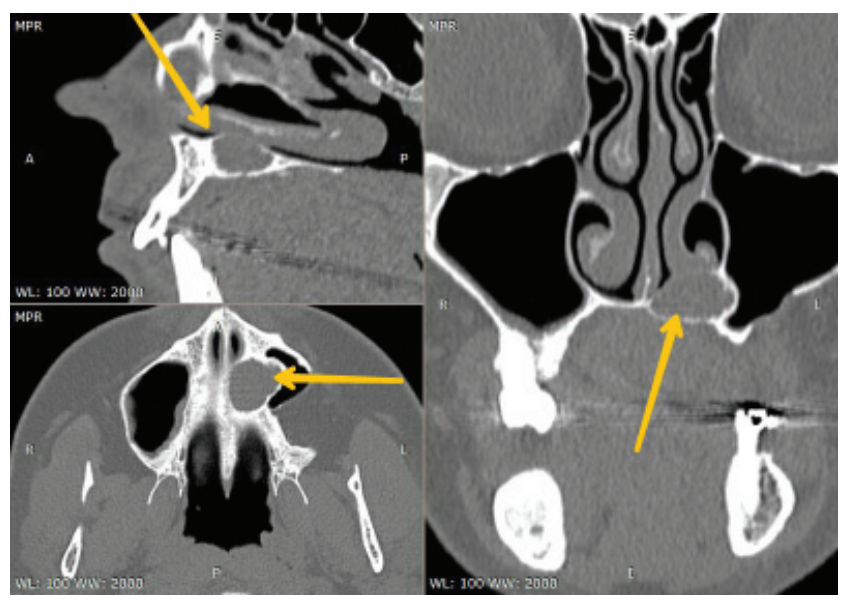

Fig. 9. Craniofacial CT - 12 months of parathyroidectomy; left maxillary tumor (yellow arrows)

the results were suggestive of osteopenia (T-score: -1.6 ; Z-score: -1.4 ; BMD: $\left.0.809 \mathrm{~g} / \mathrm{cm}^{2}\right)$. The attending endocrinologist instituted vitamin D3 supplementation.

\section{Discussion}

Brown tumor, a localized form of osteitis fibrosa cystica (fibrocystic osteitis), is a manifestation of hyperparatyroidism. At present, fibrocystic osteitis is rarely diagnosed in hyperparathyroidism as the disease is detected in its earlier stages than was the case in the past. Brown tumor usually affects the long bones; facial involvement is quite infrequent, especially in patients with multifocal lesions. It is more common in women in the $4^{\text {th }}$ and $5^{\text {th }}$ decades of life. ${ }^{4,8-10,12,14}$ In younger people, brown tumor has been reported in multiple endocrine neoplasia syndromes (MEN1 and MEN2A). ${ }^{4-6,14,15}$ Pregnancy has not been associated with brown tumor. Also, exophytic nonpedunculated lesions seen in our patient are rather uncommon. In pregnancy, clinical picture may be indicative of a pregnancy epulis or giant cell epulis. ${ }^{14,16}$ 
Histologically, brown tumors are identical to other central giant cell lesions of the jaws (CGCL) and are characterized by the presence of osteoclast-like multinucleated cells. Apart from brown tumors (brown tumors of primary, secondary and tertiary hyperparathyroidism), these lesions include central giant cell granuloma (CGCL), cherubism, aneurysmal bone cyst $(\mathrm{ABC})$, giant cell tumor of bone also referred to as osteoclastoma, and others. ${ }^{13}$ A histology report must therefore be confronted with the results of a clinical examination, laboratory tests and diagnostic imaging. ${ }^{8,10,17}$

Radiological findings tend to be noncharacteristic. Differential diagnosis includes other osteolytic lesions, most frequently solitary, with cortical thinning and tooth apex resorption, similar to odontogenic cysts and tumors. . $^{4,12}$

We believe the diagnosis of brown tumors is a complex process and should comprise the following:

- subjective and objective assessment with particular attention to symptoms characteristic of hyperparathyroidism (weakness, depression, bone and joint pain, polyuria, hypercalciuria, nephrolithiasis, loss of appetite, nausea, vomiting, constipation, gastric or duodenal ulcer, pancreatitis, cholelithiasis, hypertension, tachycardia, $1^{\text {st }}$ degree atrioventricular block, decrease in muscle strength);

- physical examination including the thyroid;

- laboratory investigations: total and ionized calcium, vitamin $\mathrm{D}$ test, serum levels of parathyroid hormone and creatinine;

- diagnostic imaging: craniofacial CT, neck ultrasonography, Tc99m scintigraphy, bone densitometry (due to the risk of PHPT-related secondary osteoporosis);

- cytology and histology: fine needle aspiration biopsy, incisional biopsy/excisional biopsy/trepanobiopsy. ${ }^{2,4,5,17,18}$

The results of laboratory tests are virtually pathognomonic for HPTH. However, accessory investigations, such as neck ultrasonography or fine needle biopsy of the parathyroids, may leave some doubts, since parathyroid adenoma/hyperplasia might be misdiagnosed as a colloid goiter or follicular neoplasm of the thyroid gland, as was the case in our patient. ${ }^{7}$

The relationship between pregnancy and brown tumor progression has not been well documented in the literature, as brown tumors are extremely rare in pregnant women. Several researchers emphasize the increased demand for vitamin D3 (resulting in suboptimal circulating 25-hydroxyvitamin D) and calcium (total calcium increases while ionized calcium remains stable) as well as PTH-related protein secretion by the placenta, decidua and mammary glands. All these mechanisms may indirectly stimulate the bone resorption processes. No relationship has been found between pregnancy and PTH secretion. ${ }^{14,16,19}$

The management of brown tumors remains controversial, but the prevailing scheme includes parathyroidectomy, long-term monitoring of osteolytic lesions and, in the case of nonresponse and/or discomfort, the surgical removal of the tumor. ${ }^{9,10,12}$ It has also been argued that expansive growth requires lesion resection followed by a parathyroidectomy. ${ }^{4,8,17}$ Other authors described conservative treatment of central giant cell granulomas with intralesional injections of corticosteroids for 6 weeks. ${ }^{20}$ Due to rapid maxillary tumor expansion in the $1^{\text {st }}$ trimester of pregnancy, our patient underwent an en bloc maxillary resection including the tumor and teeth 25, 26. Osteolytic foci were left for observation. A follow-up CT performed at 12 months after the parathyroidectomy revealed an almost complete regression of mandibular lesions, while maxillary recurrence showed only a slight regression. Considering secondary hyperparathyroidism and low vitamin D3 levels, the patient remains under close clinical observation.

Primary hyperparathyroidism may also occur in the form of an inherited disorder referred to as hyperparathyroidism - jaw tumor syndrome (HPT-JT). There are no reports on brown tumors in HPT-JT patients, but they develop fibrous tumors of mesenchymal origin. ${ }^{4,6,15,21}$

Histologically confirmed CGCL justifies the implementation of our diagnostic and treatment algorithm (Fig. 10).

As already mentioned, numerous authors emphasize diagnostic challenges of primary hyperparathyroidism. ${ }^{8,10,12}$ In our patient, the time interval between first symptoms, excision of a giant cell tumor of the clavicle and diagnosis of primary hyperparathyroidism was 24 and 12 months, respectively. Therefore, we conclude that a correct diagnosis of craniofacial brown tumors facilitates a timely diagnosis of primary hyperparathyroidism.

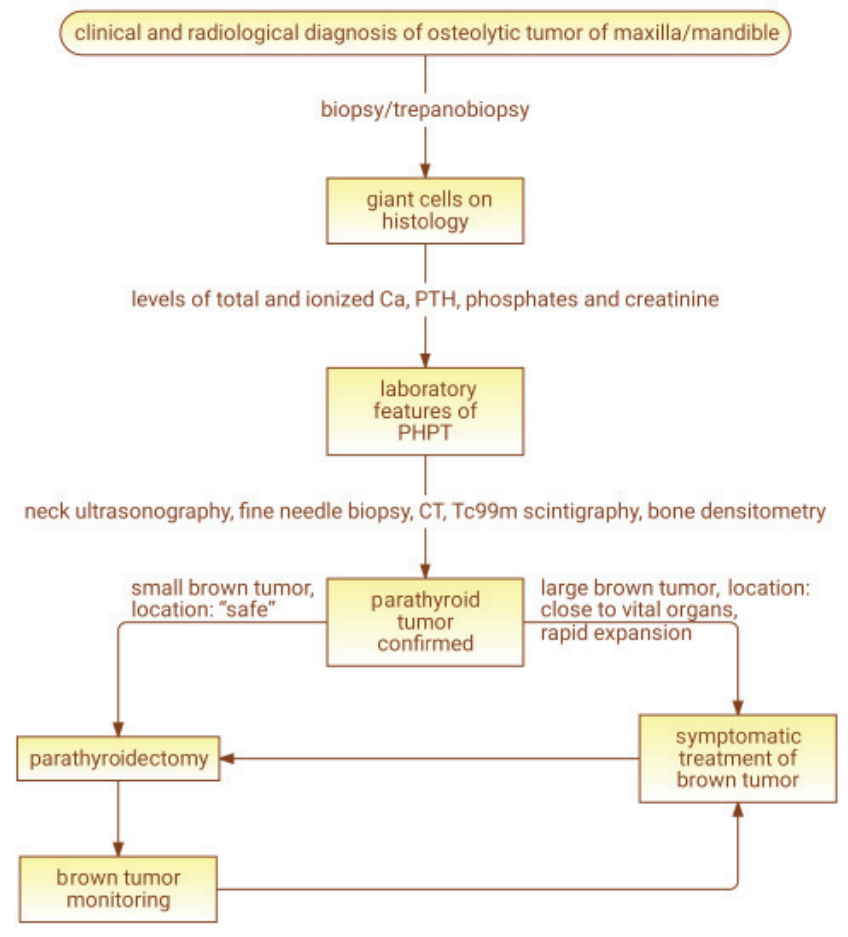

Fig. 10. Diagnostic/therapeutic scheme for brown tumor 


\section{References}

1. Pawlak W, Bolanowski M, Bohdanowicz-Pawlak A, et al. Giant cell tumor of the mandible as the first manifestation of primary hyperparathyroidism: Case report. Dent Med Probl. 2005;42:517-520 [in Polish].

2. Karwacka I, Lewandowska M, Obłończyk $Ł$, et al. PHP - primary hyperparathyroidism - permanently hidden pathology: A drama in four acts. Forum Med Rodz. 2012;6:161-167 [in Polish].

3. Drozdzowska B, Gabriel A. Diagnostyka patomorfologiczna chorób przytarczyc. In: Gawrychowski J, Jarząb B. Choroby tarczycy i przytarczyc. Diagnostyka i leczenie. $1^{\text {st }}$ ed., Warszawa: Medipage; 2014:260-268.

4. Kalapala L, Keerthi Sai S, Babburi S, et al. An endocrine jaw lesion: Dentist perspective in diagnosis. Case Rep Dent. 2016; 2016:2582038. doi:10.1155/2016/2582038.

5. Śliwa K, Marciniak M, Obłończyk $Ł$, et al. Epidemiology of primary hyperparathyroidism in people aged 55 and over. Probl Hig Epidemiol. 2010;91:248-255 [in Polish].

6. Pietkiewicz M, Nienartowicz E, Sokołowska-Dąbek D, et al. Hyperparathyroidism: Molecular, diagnostic and therapeutic aspects. Postepy Hig Med Dosw (online). 2010;64:555-567.

7. Kim HS, Choi BH, Park JR, et al. Delayed surgery for parathyroid adenoma misdiagnosed as a thyroid nodule and treated with radiofrequency ablation. Endocrinol Metab (Seoul). 2013;28:231-235.

8. Huang R, Zhuang R, Liu Y, Li T, Huang J. Unusual presentation of primary hyperparathyroidism: Report of three cases. BMC Med Imaging. 2015;15:23.

9. Shetty AD, Namitha J, James L. Brown tumor of mandible in association with primary hyperparathyroidism: A case report. J Int Oral Health. 2015;7:50-52.

10. Hakeem $\mathrm{AH}$, Hakeem IH, Wani FJ. Upper alveolar brown tumor as initial presentation of parathyroid adenoma. Natl J Maxillofac Surg. 2015;6:229-231.

11. Pawlak W, Bohdanowicz-Pawlak A, Bolanowski M, et al. Primary hyperparathyroidism presenting as giant cell tumor of the jaws. Neuroendocrinol Lett. 2013;34:107-110.

12. Soundarya N, Sharada P, Prakash N, Pradeep G. Bilateral maxillary brown tumors in a patient with primary hyperparathyroidism: Report of a rare entity and review of literature. J Oral Maxillofac Pathol. 2011;15:56-59.

13. Robinson RA, Vincent SD. Tumors and Cysts of the Jaws. $16^{\text {th }}$ ed. Maryland: Silver Spring; 2012.

14. Casteràs $A$, Darder $L$, Zafon $C$, et al. Brown tumor of the jaw after pregnancy and lactation in a MEN1 patient. Endocrinol Diab Metab Case Rep. 2016;2016:160111.

15. Krysiak R, Bartecka A, Okopień B. Rare abnormalities of parathyroid gland function and parathyroid hormone receptor action. Przegl Lek. 2014;71:36-47 [in Polish].

16. Chamarthi B, Greene MF, Dluhy RG. A problem in gestation. N Engl J Med. 2011;365:843-848.

17. Ullah E, Ahmad M, Ali SA, Redhu N. Primary hyperparathyroidism having multiple brown tumors mimicking malignancy. Indian $J$ Endocrinol Metab. 2012;16:1040-1042.

18. Gellert R. Hypo- and hypercalcemia - pathogenesis and treatment dillema. Forum Nefrol. 2011;4:373-383 [in Polish].

19. Dytfeld J, Horst-Sikorska W. Pregnancy, lactation and bone mineral density. Ginekol Pol. 2010;81:926-928.

20. Arunkumar KV, Kumar S, Deepa D. Brown tumor in mandible as a first sign of vitamin $D$ deficiency: A rare case report and review. Indian J Endocrinol Metab. 2012;16:310-315.

21. Ennazk L, El Mghari G, El Ansari N. Jaw tumor in primary hyperparathyroidism is not always a brown tumor. Clin Cases Miner Bone Metab. 2016;13:64-66. 